\title{
Manifestation of Compensatory Behavior among Preschool Children with Trust Deprivation
}

\author{
Anzhelika Polina $^{1, *}$, and Elena Ovcharova ${ }^{1}$ \\ ${ }^{1}$ Volzhsky branch "Volgograd state University", 404133 Volzhsky, Russia
}

\begin{abstract}
The article considers the problem of personal features formation among preschoolers with deprivation. The article presents the results of research aimed to reveal the peculiarities of the mental deprivation and trust deprivation among orphans, and to compare the results with the children raised in families. Many basic attitudes of the orphans are deformed, in particular, social trust relationships with the world, which are manifested in two forms of compensatory behavior. The first group comprises children with trust deprivation of passive type, characterized by anxiety, shyness, hypochondria, inability to stand up for themselves. The second group comprises children with trust deprivation of active type; these children are outwardly sociable, but they are prone to aggressive reactions, antisocial behavior and conflicts. Despite the difference in the behavior, orphans are characterized by common personal features: insecurity, inferiority, hostility, proneness to conflict, difficulties in communication.
\end{abstract}

Currently, the need to provide psychological support for children being raised under mental deprivation is becoming increasingly obvious. There are problems connected with insufficient scientific and practical development of specific areas of psychological treatment of children's development disorders in special pedagogy and psychology. One of these poorly studied areas remains the problem of psychological studies and psychocorrection of emotional and personal development of children with mental deprivation.

The problem of orphanhood and the consequences of this phenomenon increasingly become the subject of scientific researches in the fields of medicine, psychology and sociology. Modern educational system of special institutions where orphans live is ineffective in establishing the conditions for the full development of the personality. The researches of V.S. Mukhina, M.I. Lisina, I.V. Dubrovina, A.M. Prikhozhan, A.N. Tolstykh convey the idea that child-rearing within the traditional custody and guardianship model represented by the children's home, is built without giving due consideration to the adequate psychological conditions ensuring the full development of children, and inevitably impedes mental development $[1 ; 2]$.

The development of orphan's personality proceeds in a state of social and mental deprivation which has a negative effect on the development of emotional and personal areas, communication, self-acceptance and selfassessment of a child [3]. As a result, many basic attitudes of children are deformed; they are connected with full social integration, particularly social trust relationships with the world and its various dimensions. The term "mental deprivation" describes situation, nature and typical effects of deprivation, which are principal and essential for optimal development of functions and processes [4]. Situations which can represent deprivation factor, are various and complicated. Deprivation conditions have different impact on the children of different age. With age, children's needs as well as sensitiveness to their insufficient satisfaction change [2; 5].

Researchers J. Langmeier and Z. Matejcek describe mental deprivation as "the psychological state that occurs as the result of one's living conditions when the subject is unable to satisfy his basic psychological needs at sufficient level and in sufficient space of time" [4].

As is well-known from works of many researchers (V.P. Zinchenko, T.P. Skripkina, P.N. Shikhirev, B.S. Bratus, E. Eriksson, T. Yamagisha, A. Seligmen J. Allen, E. Giddens, B. Johnson, K. Dzhifin, $\mathrm{S}$. Dzhudard), the trust is the basic factor defining psychological wellbeing in human life.

Based on the analysis of literary sources we found it possible to classify the deficiency of trust relationships of children being raised in the conditions of children's home as trust deprivation. By trust deprivation, we mean not just child's unsatisfied need for trust relationships with other people, but also insufficient development of the need for trust relationships itself [1].

According to the concept developed by T.P. Skripkina, principal universal conditions for the origin of trust are safety and significance of the trust object, for this reason trust deprivation is deprivation of a child's feeling of safety and security in social environment [6].

As is well-known from works of many researchers,

\footnotetext{
* Corresponding author: a.polina71@mail.ru
} 
trust is the basic factor defining psychological wellbeing in human life. Based on this statement, it is possible to assume that trust deprivation which is formed initially, at the earliest stages of ontogenesis as lack of global feeling of safety and security by close people, also belongs to significant factors of a mental deprivation [1].

In this regard, we will consider the analysis of works of both Russian and foreign scientists concerning a trust problem. So based on the researches by T.P. Skripkina, we understand the trust phenomenon via the integration mechanism of people trust to themselves and at the same time trust to the world. It allows considering trust as the social and psychological phenomenon, which is formed thanks to interaction of two multidirectional positions social and personal [6].

The representative of social learning theory, R. Sears considered that the most essential need of a preschooler is the need for attachment, which cannot be ignored. Based on the known behavioral characteristics of children being raised in the conditions of children's home connected with their obsession with any new adult, it can be assumed how frustrated their need for attachment is. Adhering to the point of view of R.R. Sears, we consider that frustration of need for attachment is connected with lack of basic feeling of safety and related lack of sense of security [7]. Naturally, on this basis trust to other people both adults and peers is not formed, and it is known from empirical researches that self-trust is formed on the basis of trust of close adults to the child.

In other words, orphans do not have that primary base on which trust relationships can be formed. As a result, children without parents are subject to trust deprivation. In respect of words spoken, it becomes clear that children being raised in the conditions of children's home have trust deprivation which results, on the one hand, in development of the inadequate ways of interaction with people connected with the increased conflictness, aggression and the general not constructive character of the relations, and on the other hand, all this is connected with deformations of the personality [1].

Trust to the world, openness to perception of the new are possible only when there is a feeling of constant care and attention of the loving adult. The children being raised in closed institutions, experience deficiency of affection, attention, emotional warmth from parents and other adults and therefore they have no confidential attitudes towards people around. As a result, children of this category have low self-esteem, their emotional sphere is broken, the world around is distorted and leads to deformation of selftrust and trust to the world $[1 ; 2 ; 6]$. Students of boarding institutions are characterized by being behind in the following areas of mental development: in the sphere of communication with adults; in the sphere of communication with peers; in consciousness; in the emotional-volitional sphere [8]. The emotional-volitional sphere of the orphan is characterized by: the lowered mood background; monotony of emotional and expressional means of communication; tendency to fast change of mood; emotional superficiality; inadequate forms of emotional response to approvals and remarks; the increased tendency to fears, uneasiness, anxiety; misunderstanding of an emotional condition of other person [9].

Incompleteness of emotional life in orphan institutions causes decrease of the activity among some of the children, which leads to apathy and bigger interest in things, than in people at more advanced age. And among other children - hyperactivity with retreat into asocial and criminal activity; many children tend to behave provocatively in society trying to draw attention to themselves with inability to create strong emotional attachments $[5 ; 10]$.

Children with undeveloped mindset to trust other people cannot create adequate values about themselves, and therefore some personal characteristics of these children are subject to deformation. Most often, this is manifested in low self-esteem, uncertainty, aggression, hostility, vulnerability, shyness and compensatory behavior [11].

Therefore, a number of important issues is unresolved at the moment; they are special aspects of trust/ mistrust of preschoolers being raised in closed institutions, role of trust in personal development of preschoolers, influence of trust deprivation on compensatory behavior.

The initial idea of the empirical study was to study deformation of trust relations of the children being raised in children's homes. During the first pilot study and the selection of methods aimed to detect social trust relationships ("Two Houses" (I. Vandvik, G. Eckblad), "The Kindest - the meanest" (V.S. Mukhina)), along with monitoring of the residents of the children's homes, it turned out that it is impossible to study trust relationships deformation since orphans do not have trust relationships. In the early ontogeny, orphans' need of close adult and the need of safety are not satisfied, which is why basic trust affirmations are not developed. In this regard, we have introduced the term "trust deprivation" [1]. Deprivation of social trust of the children living in the children's homes affects emotional, personal and behavioral spheres of a child. In other words, trust deprivation is the cause of a significant number of underlying personal deformations.

In this connection, we have carried out a psychodiagnostic research aimed to reveal the peculiarities of the mental deprivation and trust deprivation among orphans, and compare the results obtained during the examination of the children raised in families. The research was performed on the basis of Volzhsky Public Children Foundation; Psychosocial Support Center "Semia" Volzhsky, and on the basis of Kindergarten №.75.

Children being raised in deprivation conditions could not develop the adequate system of values towards themselves, and therefore, some personal characteristics of these children are subject to deformation. In most cases, it is evidenced in low self-esteem, lack of confidence, aggression, hostility and other persona characteristics. In order to reveal deformation of the 


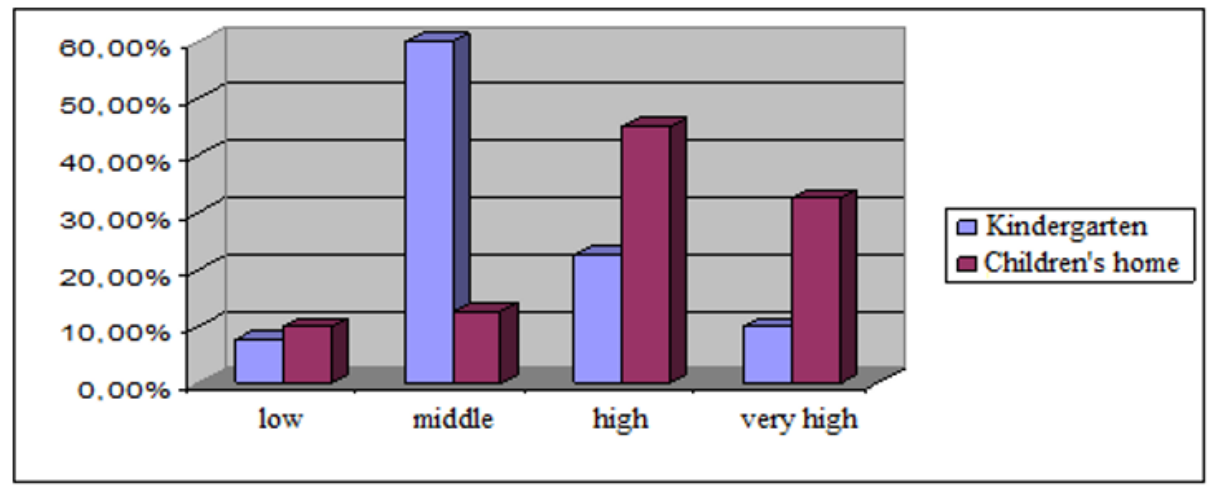

Fig. 1. General level of symptom-complexes among pre-schoolers.

above-mentioned personal characteristics, the projective technique of personal traits evaluation - "House-TreePerson" (J. Buck, modified by R.F. Bieliauskaitè) was used. According to the requirement of the technique, the following principal symptom-complexes of child's personality can be revealed by means of this research; they are vulnerability, anxiety, self-assessment, sense of inferiority, hostility, proneness to conflict, poor rapport. The results obtained are reflected in Fig.1.

Children with a high and very high level of symptomcomplexes (mostly these are children from children's homes) have serious communication problems because of the fact that their social attitude to trust is deprived. Most often, these children are very anxious, conflictive, and aggressive; as consequence, such children do not build trust in themselves and the world as a whole. A child usually conceals insecurity, vulnerability, inability to communicate with the people around to whom he or she projects his or her aggression, behind hostile and conflict behavior. Such reaction of a child to communication is one of the compensatory forms of behavior.

Negative emotions of such children are manifested in many activities, relationships and communication. Thus, when they received an assignment related to drawing, many of them refused to draw referring to the "lack of skill", waited for a long time watching others drawing. Emotional deprivation and inner discomfort of the children of this group are vividly depicted in the pictures: in aggressive poses of people, the picture is covering the entire sheet of paper. The color range of the pictures is usually monotone. The picture is more often drawn with a black pencil, extremely primitive. These children got the highest score for the symptoms of hostility, anxiety, proneness to conflict and poor rapport.

Children of passive type are also among the high and very high level of symptom-complexes. Hypersusceptibility, unsociability, embarrassment, shyness, tearfulness, inability to stand up for themselves are peculiar to them. In this case, compensatory form of behavior is represented by avoiding communication. During drawing, they covered the picture with a hand, constantly doubted. During the interpretation of the pictures, they were defined to have symptoms of anxiety, vulnerability and sense of inferiority. This is shown by such peculiarities of the pictures as forceful hatching, faint broken line of the drawing, small size of the picture, etc.

Children with a low level of symptom-complexes are not always distinguished by positive dynamics of emotions and social trust relationships development. Some children of this group as well as children referred to the high and very high level of symptom-complexes, have problems. These children are distinguished by over unconventional behavior; they mostly ignore rules and standards of behavior. For this reason, they act the way they want at the moment. Children of this level have a low level of anxiety, very poor self-control, more often inadequately high self-esteem. According to the obtained data, it is evident that there is a small amount of such children both in children's home and in kindergarten and the number is approximately the same. This group of children also demonstrates compensatory forms of behavior connected with protective functions of the individual self.

The behavior of the children with the middle level of symptom-complexes is the most adequate. The results demonstrated a huge difference between experimental and control group. This group comprises active, open children with a high level of social trust relationships development. Points for each symptom-complex were calculated separately in order to reveal which problem is more connected with manifestation of trust deprivation (fig. 2).

The general picture of symptom-complexes of children from two groups is very different in percentage terms, particularly as occurrence of the same symptom among children from children's home and children from the family varies in the intensity of its manifestation. Such leading indicators of symptom-complexes such as the level of vulnerability, sense of inferiority are illustrative of the significance of adult's protection for the children of this age, against which basic trust is developed.

Further, discrepancies in the intensity of symptomcomplexes are evident. Thus, the following indicators of symptom-complexes among orphans are proneness to conflict $(57.5 \%)$ and anxiety (55\%). The symptomcomplexes indicator "hostility" is also high $-47.5 \%$. In comparison with the children from the family, symptomcomplexes indicators are rather low: proneness to conflict $-17.5 \%$, hostility $-12.5 \%$. 


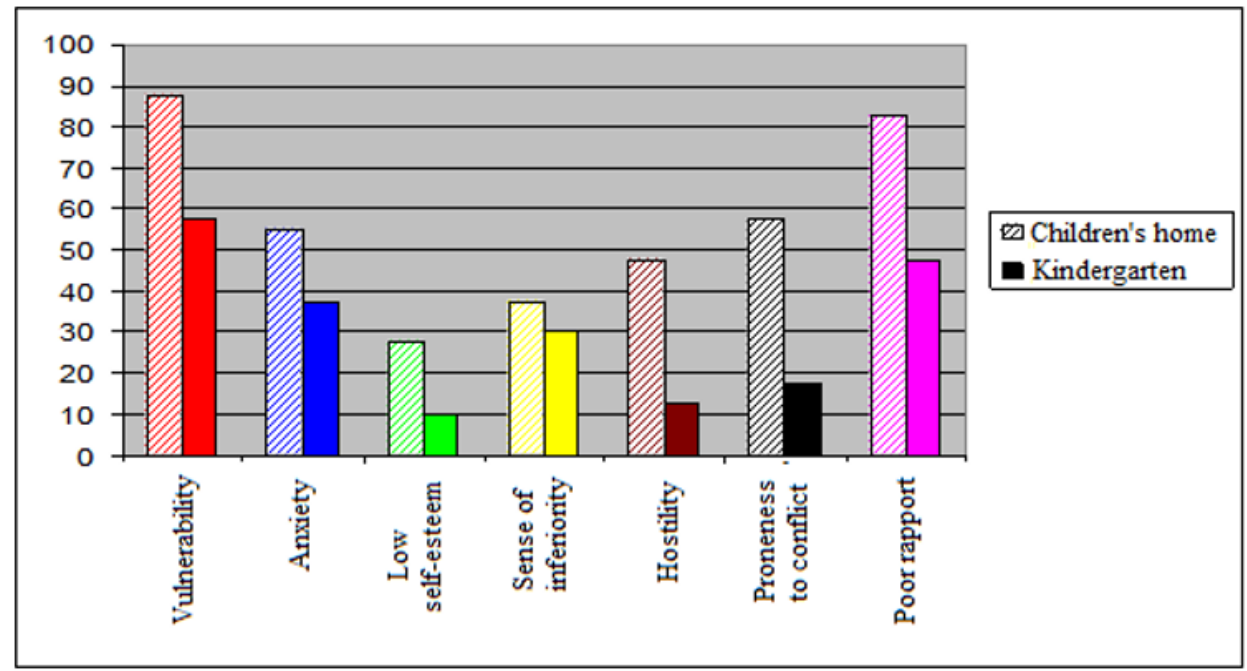

Fig. 2. Indicators of individual symptom-complexes as per "House-Tree-Person" test.

In order to detect statistical significance of the differences between indicators of two groups of children, Student's t-criterion was applied. Comparative results of symptom-complexes intensity as per "House-TreePerson" test in two examined groups at the ascertaining stage of the experiment are displayed in table 1 .

As Table 1 shows, an intensity level of a larger number of symptom-complexes as per "House-TreePerson" test in the group of children from the children's home is significantly higher than one in the group of children from the kindergarten. Thus, differences between average values of symptom-complexes of two examined groups are statistically significant; consequently, children with trust deprivation have pronounced symptom-complexes as per all parameters under examination: they are characterized by sense of inferiority, high level of anxiety, hostility and poor rapport.

Occurrence of the pronounced and specified symptom-complexes results not only from the lack of social communication experience of orphans but also from the lack of trust on the part of the people around them especially adults; consequently, the child feels unprotected and experiences high level of anxiety. As a result, the child does not develop skills of normal constructive communication which assumes trusting other people; hence, intensity of qualities connected with hostility and aggression. All this is resulting in reduction of self-esteem and occurrence of inferiority sense, which in turn, are connected with the failure to develop selftrust affirmation.

Accordingly, only $12,5 \%$ of the children from the children's home are not subject to trust deprivation, which means they tend to develop social trust relationships. The rest $87,5 \%$ are the children with the problems in interpersonal relationships; they are subject to various symptom-complexes caused by trust deprivation. This statement leads to the conclusion that along with trust deprivation, children being raised in the conditions of children's home are characterized by lack of an axiological attitude to themselves resulting in expression of self-distrust [6].

The summarized analysis of the results and monitoring of children during the diagnostic procedure resulted in identification of two distinctive forms of compensatory behavior, which are conditionally divided into two groups. The first group comprises children with trust deprivation of passive type, they are characterized by anxiety, shyness, hypochondria, inability to stand up for themselves, they are sensitive to the opinion regarding themselves expressed by the other people, they avoid communication being afraid of disapproval from adults. Children of this type are characterized by low selfesteem. These difficulties along with emotional sensitivity of such children often lead to building of barriers to communication, avoidance, and contacts minimization.

Children of this group belong to the middle and high levels of symptom-complexes. Such symptom-complexes as vulnerability, sense of inferiority, lack of confidence are particularly pronounced. Children with passive type of compensatory behavior are also characterized by middle and low levels of emotional reactions, as manifested in some kind of restraint, awareness in social situations.

Communication deficiency causes painful experiences and deepens development of trust deprivation. Such children are generally characterized by conformist reactions; they rarely pick a fight, easily plead guilty in a difficult situation. These are the children who poorly reflect emotional state of the interlocutor and do not trigger respondent sympathy and desire to remain in contact. 
Table 1. Indicators of individual symptom-complexes as per "House-Tree-Person" test.

\begin{tabular}{|c|c|c|c|c|c|}
\hline No & $\begin{array}{c}\text { Name of symptom- } \\
\text { complexes }\end{array}$ & $\begin{array}{c}\text { Average } \\
\text { value, } \\
\text { kindergar } \\
\text { ten group }\end{array}$ & $\begin{array}{c}\text { Average } \\
\text { value, } \\
\text { children's } \\
\text { home group }\end{array}$ & $\begin{array}{c}\text { Average } \\
\text { values } \\
\text { difference }\end{array}$ & $\begin{array}{c}\text { Signi } \\
\text { fican } \\
\text { ce } \\
\text { level } \\
P\end{array}$ \\
\hline 1 & Vulnerability & 2.85 & 5.025 & 2.175 & 0.01 \\
\hline 2 & Anxiety & 3.225 & 3.925 & 0.7 & 0.01 \\
\hline 3 & Hostility & 1.225 & 1.675 & 0.45 & 0.01 \\
\hline 4 & $\begin{array}{c}\text { Proneness to } \\
\text { conflict }\end{array}$ & 1.75 & 3.275 & 1.525 & 0.01 \\
\hline 5 & Poor rapport & 3.375 & 5 & 1.625 & 0.01 \\
\hline
\end{tabular}

At the same time their emotional insulation, conflict avoidance and a low level of interest in such communication lessen negative consequences of their isolation resulting in reduction of self-esteem and selfconfidence. Trust deprivation is manifested through the high level of suspicion, emotional closedness, uncertainty, anxiety, inadequate self-esteem and poor motivation for communication. Barriers to communication, tendency towards avoidance, contacts minimization are generally blocked by the process of development of confidence in the world.

The second group comprises children with trust deprivation of the active type; they are outwardly sociable and active, they have inadequate, more often inflated than deflated self-esteem, they are ostentatious, aggressive. Many children of this type have some adverse symptomcomplexes with high score: proneness to conflict, vulnerability, poor rapport, hostility.

These children tend to blame other people in conflict situations; that is why, they are characterized by excessive proneness to conflict, expansiveness, aggression, hostility. Negative emotions of such children are demonstrated in different activities, relationships.

As a rule, they are ostentatious, very impulsive, overexcitable; however, emotional instability does not allow them to control their negative emotions to an adequate degree. Their emotional reactions often proceed in the form of violent outbreaks of discontent, offence, anger that can result in aggressive behavior in adverse conditions.

Children of active type are also characterized by excessive unselfconsciousness, general lack of sense of distance, susceptibility, excitability. During initial relationships building, these children are very active, but in later communication, they also close themselves up and often avoid relationships like the children of the first subgroup. Despite outward sociability, these children can demonstrate trust deprivation, which is manifested through emotional vulnerability, a high level of anxiety, nonconstructive nature of interpersonal relations, a low level of self-direction and inadequacy of sense perception.

Moreover, as a result of the characteristics specified above children with trust deprivation turn out to have undeveloped adequate modes of behavior. Their behavior is not focused on the establishment of normal human contact, development of joint play activity and cooperation skills; it simply comes down to protection of the individual self in terms of compensatory behavior.

Therefore, children with mental deprivation and trust deprivation of the first and the second groups are characterized by vulnerability, sense of inferiority, hostility, proneness to conflict, poor rapport. For this reason, despite the outward differences in behavior of the children from two groups, they share common problems connected with the lack of trust in other people and in themselves.

Above all, child's need for love and acceptance shall be satisfied for the full development. Dissatisfaction of this basic need results in distortion of personal development, occurrence of trust deprivation and compensatory behavior. The earlier the child gets help in development of trust relationships experience, the less his or her mental development and relations with other people suffer. Corrective actions aimed to develop trust relationships and adequate modes of behavior shall be of a complex nature including rehabilitation of negative social experience by means of development of cooperation skills as well as methods of self-direction of negative and aggressive acts in conflict situations.

\section{References}

1. A.V. Polina, Bulletin of the Yaroslavl state university of P.G. Demidov. Series Humanities 4/1 (22/1), 215 (2012)

2. V.N. Oslon, Psychological Science and Education 21(1), 146-155 (2016)

3. T. O. Archakova, A. N. Veraksa, O. Y. Zotova, E. B. Perelygina, Psychological Science and Education 22(6), 68-76 (2017)

4. J. Langmeier, Z. Matejcek, Psychological Deprivation in Childhood (Prague, 1984)

5. T. I. Shulga, Psychological Science and Education 2, 203 (2013)

6. T.P. Skripkina, The System of the Trust Relationships in Developmental and Self-developmental Psychology of Subject and Subjectivity: The Principle of the Development in Modern Psychology, Ser. "Methodology, theory and History of Psychology" 
(Institute of Psychology of Russian Academy of Sciences, M, 2016)

7. R. Sears, E.E. Maccoby, H. Levin, Patterns of child rearing (Evanston, 1957)

8. I.V. Polyakova, Science journal of Volgograd State University. Ser. 11, Natural Sciences 2 (12), 113-121 (2015)
9. J. Bowlby, A secure base: Parent-child attachment and healthy human development (N.Y., 1988)

10. Y.A. Kochetova, Psychological Science and Education 3, 77-87 (2012)

11. E.V. Ovcharova, Modern Problems of Science and Education 2 (2015) 